\title{
Unified Analytical Formulae of Second Virial Coefficient with Kihara Potential and its Application to Real Gases
}

\author{
E. Somuncu ${ }^{a, *}$, M. EmeK ${ }^{b}$, B.A. MAmedov ${ }^{c}$ \\ ${ }^{a}$ Department of Physics, Faculty of Arts and Sciences, Giresun University, Giresun, Turkey \\ ${ }^{b}$ GolbasıVocational School, Adıyaman University, Adıyaman, Turkey \\ ${ }^{c}$ Department of Physics, Faculty of Arts and Sciences, Gaziosmanpasa University, Tokat, Turkey \\ (Received March 28, 2019; revised version December 26, 2019; in final form January 28, 2020)
}

\begin{abstract}
We propose a general evaluation method to calculate the second virial coefficient with Kihara potential (spherical core). The suggested approach is based on exponential function series expansion formula and gamma functions, which enable us to have accurate evaluation of the second virial coefficient. The results of second virial coefficient determined from Kihara potential are compared with the calculations of second virial coefficient with LennardJones (12-6) potential. The analytical formula allows an accurate determination of Boyle temperature of gases. The accuracy of the obtained formula is tested by its application to gases $\mathrm{Ar}, \mathrm{Kr}, \mathrm{Ne}, \mathrm{CH}_{4}, \mathrm{C}_{6} \mathrm{H}_{6}, \mathrm{C}_{3} \mathrm{H}_{8}, n$ - $\mathrm{C}_{4} \mathrm{H}_{10}$, and $n-\mathrm{C}_{5} \mathrm{H}_{12}$. The results of the second virial coefficient in a wide temperature range and Boyle temperature are in good agreement with the data available in the literature.
\end{abstract}

DOI: 10.12693/APhysPolA.137.293

PACS/topics: virial equation of state, second virial coefficient, Kihara potential, real gases

\section{Introduction}

The evaluation of the virial coefficients is an important issue to determine intermolecular interactions with arbitrary values of temperature and thermodynamic properties of real gases [1-8]. In literature, several experimental and theoretical methods have been proposed to obtain accurate and efficient evaluation of the second virial coefficient with various types of potentials [9-16]. The Lennard-Jones $(2 n-n)$ potential that is important to define the interaction between simple spherical molecules only, has been widely studied by both experimental and theoretical methods [17]. Kihara potential is defined of the interaction between two more complex molecules and found wide applications because it is superior to Lennard-Jones (12-6) potential for determination of virial coefficients, thermodynamic and transport properties [18-20]. There are also some restricted studies on the analytical evaluation of second virial coefficient with Kihara potential [20-22]. In spite of many studies, the applications of the second virial coefficient for various types of the intermolecular interaction are still one of the main actual problems in physics and biophysical chemistry [23-25].

In this paper, an efficient analytical formula for the second virial coefficient with Kihara potential is presented. For some of gases, examples of applications are given to demonstrate the efficiency of the present analytical expression. For gases $\mathrm{Ar}, \mathrm{Kr}, \mathrm{Ne}, \mathrm{CH}_{4}, \mathrm{C}_{6} \mathrm{H}_{6}, \mathrm{C}_{3} \mathrm{H}_{8}$,

\footnotetext{
*corresponding author; e-mail: elf_smnc@hotmail.com
}

$n$ - $\mathrm{C}_{4} \mathrm{H}_{10}$, and $n-\mathrm{C}_{5} \mathrm{H}_{12}$, we have calculated the Boyle temperature by using obtained formula. The calculation results for the second virial coefficient with Kihara potential and its implementation to the various gases indicate a good rate of convergence and numerical stability.

\section{Expressions for the Second Virial Coefficient with Kihara Potential and Boyle Temperature}

The second virial coefficient in terms of intermolecular potential $u\left(r_{i j}\right)$ are given in the following forms [21]

$$
B_{2}(T)=-2 \pi N_{\mathrm{A}} \int_{0}^{\infty} r_{12}^{2}\left(\mathrm{e}^{-u\left(r_{12}\right) / k_{\mathrm{B}} T}-1\right) \mathrm{d} r_{12}
$$

where $N_{\mathrm{A}}$ is Avogadro's constant, $k_{\mathrm{B}}$ is the Boltzmann constant and $T$ is temperature. The physical significance of second virial coefficient is that it demonstrates the first deviation from ideality $[21,26,27]$. The temperature at which $B_{2}(T)=0$ is called the Boyle temperature [27]. At Boyle temperature, the gases appear to behave ideally.

For evaluation of the second virial coefficient, we use the Kihara potential for molecules with spherical cores of the following form [22]:

$$
u(r)= \begin{cases}\infty & r<d \\ 4 \varepsilon\left[\left(\frac{\sigma-d}{r-d}\right)^{12}-\left(\frac{\sigma-d}{r-d}\right)^{6}\right] & r \geq d\end{cases}
$$

where $d$ is the radius of spherical molecular core, $\varepsilon$ is the depth of the potential well, $\sigma$ is the collision diameter, and $r$ is the distance between the particles [28]. Equation (2) gives the Lennard-Jones (12-6) potential, when $d=0$ [28]. 
Inserting (2) into (1) leads to

$$
B_{2}\left(T^{*}\right)=-2 \pi N_{\mathrm{A}}\left(\frac{\sigma}{1+a^{*}}\right)^{3}\left\{-\int_{0}^{a^{*}} x^{2} \mathrm{~d} x+\int_{a^{*}}^{\infty}\left[\exp \left(-\frac{4}{T^{*}}\left(\left(x-a^{*}\right)^{-12}-\left(x-a^{*}\right)^{-6}\right)\right)-1\right] x^{2} \mathrm{~d} x\right\},
$$

where $T^{*}=k_{\mathrm{B}} T / \varepsilon, r / \sigma-d=x, d / \sigma-d=a^{*}$, and $d=a^{*} \sigma /\left(1+a^{*}\right)$. By applying partial integral to the second term in (3), we obtain the following formula:

$$
\begin{aligned}
& B_{2}\left(T^{*}\right)=-2 \pi N_{\mathrm{A}}\left(\frac{\sigma}{1+a^{*}}\right)^{3} \frac{4}{3 T^{*}} \\
& \quad \times \int_{a^{*}}^{\infty} \exp \left(-\frac{4}{T^{*}}\left(\left(x-a^{*}\right)^{-12}-\left(x-a^{*}\right)^{-6}\right)\right)\left(-12\left(x-a^{*}\right)^{-13}+6\left(x-a^{*}\right)^{-7}\right) x^{3} \mathrm{~d} x .
\end{aligned}
$$

To evaluate integrals we use a well-known series formula of exponential functions as [29]

$$
e^{ \pm x}=\sum_{n=0}^{N}( \pm 1)^{n} \frac{x^{n}}{n !}
$$

By subsisting (5) into (4), we have

$$
\begin{aligned}
& B_{2}\left(T^{*}\right)=2 \pi N_{\mathrm{A}}\left(\frac{\sigma}{1+a^{*}}\right)^{3} \\
& \quad \times\left[\frac{8}{T^{*}} \lim _{N=\infty} \sum_{n=0}^{N} \frac{\left(4 / T^{*}\right)^{n}}{n !} \int_{a^{*}}^{\infty} \exp \left(-\frac{4\left(x-a^{*}\right)^{-12}}{T^{*}}\right)\left(x-a^{*}\right)^{-6 n}\left(2\left(x-a^{*}\right)^{-13}-\left(x-a^{*}\right)^{-7}\right) x^{3} \mathrm{~d} x\right] .
\end{aligned}
$$

Further, solving integral in (6) allows to obtain

$$
\begin{aligned}
& B_{2}\left(T^{*}\right)=\frac{8 \pi N_{\mathrm{A}}}{3 T^{*}} \lim _{N=\rightarrow \infty} \sum_{n=0}^{N} \frac{\left(4 T^{*}\right)^{n}}{n !} \\
& \times(\sigma-d)^{12+6 n}\left[d^{3}\left(\frac{4 / T^{*}}{(\sigma-d)^{-12}}\right)^{-\left(\frac{n}{2}+1\right)} \Gamma\left(\frac{n}{2}+1\right)+3 d^{2}\left(\frac{4 / T^{*}}{(\sigma-d)^{-12}}\right)^{-\left(\frac{n}{2}+\frac{11}{12}\right)} \Gamma\left(\frac{n}{2}+\frac{11}{12}\right)\right. \\
& \left.+3 d\left(\frac{4 / T^{*}}{(\sigma-d)^{-12}}\right)^{-\left(\frac{n}{2}+\frac{5}{6}\right)} \Gamma\left(\frac{n}{2}+\frac{5}{6}\right)+\left(\frac{4 / T^{*}}{(\sigma-d)^{-12}}\right)^{-\left(\frac{n}{2}+\frac{3}{4}\right)} \Gamma\left(\frac{n}{2}+\frac{3}{4}\right)\right] \\
& -\frac{1}{2}(\sigma-d)^{-6}\left[d^{3}\left(\frac{4 / T^{*}}{(\sigma-d)^{-12}}\right)^{-\left(\frac{n}{2}+\frac{1}{2}\right)} \Gamma\left(\frac{n}{2}+\frac{1}{2}\right)+3 d^{2}\left(\frac{4 / T^{*}}{(\sigma-d)^{-12}}\right)^{-\left(\frac{n}{2}+\frac{5}{12}\right)}+\frac{5}{12}\right) \\
& \left.+3 d\left(\frac{4 / T^{*}}{(\sigma-d)^{-12}}\right)^{-\left(\frac{n}{2}+\frac{1}{3}\right)} \Gamma\left(\frac{n}{2}+\frac{1}{3}\right)+\left(\frac{4 / T^{*}}{(\sigma-d)^{-12}}\right)^{-\left(\frac{n}{2}+\frac{1}{4}\right)} \Gamma\left(\frac{n}{2}+\frac{1}{4}\right)\right]
\end{aligned}
$$

With the use of function

$$
H(u, k)=\lim _{N \rightarrow \infty} \sum_{t=0}^{N}\left(4 / T^{*}\right)^{t}\left(\frac{\sigma}{1+a^{*}}\right)^{12+6 t} u^{-\frac{6 t+k}{12}} \Gamma\left(\frac{6 t+k}{12}\right)
$$

simpler form of (7) can be obtained, namely:

$$
\begin{aligned}
& B_{2}\left(T^{*}\right)=\frac{8 \pi N_{\mathrm{A}}}{3 T^{*}} \\
& \quad \times\left\{d^{3} H\left(\frac{4 / T^{*}}{(\sigma-d)^{-12}}, 12\right)+3 d^{2} H\left(\frac{4 / T^{*}}{(\sigma-d)^{-12}}, 11\right)+3 d H\left(\frac{4 / T^{*}}{(\sigma-d)^{-12}}, 10\right)+H\left(\frac{4 / T^{*}}{(\sigma-d)^{-12}}, 9\right)\right. \\
& \left.\quad-\frac{1}{2}(\sigma-d)^{-6}\left[d^{3} H\left(\frac{4 / T^{*}}{(\sigma-d)^{-12}}, 6\right)+d^{2} H\left(\frac{4 / T^{*}}{(\sigma-d)^{-12}}, 5\right)+3 d H\left(\frac{4 / T^{*}}{(\sigma-d)^{-12}}, 4\right)+H\left(\frac{4 / T^{*}}{(\sigma-d)^{-12}}, 3\right)\right]\right\}
\end{aligned}
$$


where $N$ is the upper limits of summation. The reduced second virial coefficient is $B_{2}^{*}\left(T^{*}\right)=B_{2}\left(T^{*}\right) / b_{0}$, where $b_{0}=\frac{2 \pi}{3} N_{\mathrm{A}} \sigma^{3}$. The quantity $\Gamma(\alpha)$ is well known gamma function defined by [29]

$$
\Gamma(\alpha)=\int_{0}^{\infty} \mathrm{e}^{-t} t^{\alpha-1} \mathrm{~d} t
$$

In this paper, we calculate the Boyle temperature $T_{\mathrm{B}}$ by using the following condition in (9):

$$
B_{2}\left(T_{\mathrm{B}}^{*}\right)=0
$$

\section{Numerical results and discussion}

In this work, the second virial coefficient with Kihara potential has been studied with the analytical evaluations. The Mathematica 7.0 international software has been used to calculate the analytical expression. The second virial coefficients with Kihara potential and Lennard-Jones (12-6) potential have been plotted and the influence of parameters values on the results have been analyzed. The results show that the obtained expression is general and valid for arbitrary values of parameters. The calculated results are compared with the corresponding experimental and other theoretical values $[20,22,30]$. The accuracy of analytical method is satisfactory and can be suggested for evaluation of thermodynamic properties of gases by using second virial coefficient.

A theoretical method based on the gamma function was used for the evaluation of second virial coefficient with Kihara potential in $[5,20,31]$. The difference between $[5,20,31]$ and the results in this paper is caused by the analytical calculation method. To show the effectiveness of the proposed method we apply it for molecules $\mathrm{Ar}, \mathrm{Kr}, \mathrm{Ne}, \mathrm{CH}_{4}, \mathrm{C}_{6} \mathrm{H}_{6}, \mathrm{C}_{3} \mathrm{H}_{8}$, $n$ - $\mathrm{C}_{4} \mathrm{H}_{10}$, and $n-\mathrm{C}_{5} \mathrm{H}_{12}$. In Tables I-III, the accuracy of the analytical formula is demonstrated by comparison of different results from experimental data, theoretical data $[5,20,31]$, and Lennard-Jones (12-6) potential results $[15,21]$. As can be seen from Table II, the obtained results for the second virial coefficient of Kihara potential by using different parameter values are in better agreement with experimental data than [20] and/or the calculated results of the second virial coefficient with Lennard-Jones (12-6) potential.

As it is demonstrated in Table IV, the convergence properties of (9) with those in [20] change wildly. The most rapid convergence to the numerical results for different values of $T^{*}$ shows (9). The calculations have been made with the upper limits $N=50$ series.

The examples of calculations of (9) for gases $\mathrm{Ar}$, $\mathrm{Kr}, \mathrm{Ne}, \mathrm{CH}_{4}, \mathrm{C}_{6} \mathrm{H}_{6}, \mathrm{C}_{3} \mathrm{H}_{8}, n-\mathrm{C}_{4} \mathrm{H}_{10}$, and $n-\mathrm{C}_{5} \mathrm{H}_{12}$ are presented in Tables I-III and Figs. 1, 2. It is understood from the resolution of the graphics that the results are in good agreement with data available in literature [27-29]. For a wide range of temperature the results of (9) show agreement with the literature $[20,22,32]$. However, for increased values of $a^{*}$ there is less agreement. Examples for $a^{*}=0$ (Lennard-Jones limit) are given in Table I. The results of the calculation according to Eq. (9) agrees with those in $[15,21]$. In Figs. 1, 2 we compare our studies with results from $[22,30]$ and the agreements are satisfactory. Also, the results of second virial coefficient for Kihara potential show a good agreement with calculated results of second virial coefficients determined from LennardJones (12-6) potential [32]. The reduced Boyle's temperature, obtained by us using the second virial coefficient, is $T_{\mathrm{B}}^{*}=2.8771$ [33]. At this temperature real gas is considered as an ideal gas.

The parameters of Lennard-Jones (12-6) potential $[15,34]$ and Kihara potential $[22,28]$ are represented in Table $\mathrm{V}$ for gases $\mathrm{Ar}, \mathrm{Kr}, \mathrm{Ne}, \mathrm{CH}_{4}, \mathrm{C}_{6} \mathrm{H}_{6}, \mathrm{C}_{3} \mathrm{H}_{8}$, $n-\mathrm{C}_{4} \mathrm{H}_{10}$ and $n-\mathrm{C}_{5} \mathrm{H}_{12}$. These gases are used widely in industry, and in scientific and engineering applications, thus the analytical expression provides the access to exact calculation of second virial coefficient with Kihara potential. The obtained results for the second virial coefficient by using different parameter values of Kihara potential are shown in Table II. The presented values are very close to each other. As can be seen from Table II, the calculated second virial coefficient as a function of temperature when compared with experimental values show very good agreement. In fact, this agreement is even better than for those using the Lennard-Jones (12-6) potentials.

To sum up, further academic backgrounds and further discussion of their results are required. The main contribution of this work is the addition of new relationships of the well-known second virial coefficient of Kihara potential with spherical core. In addition, the accuracy of computation is analyzed and a theoretical assessment of virial to real gases has been performed.

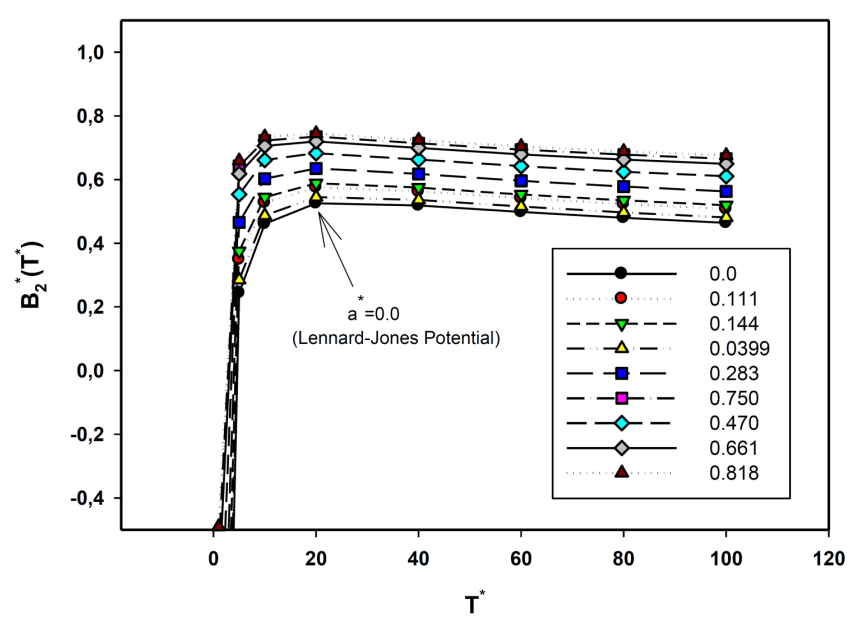

Fig. 1. The reduced temperature dependence of reduced second virial coefficients various $a^{*}$ of potential parameter. 
Calculation results of second virial coefficient $B_{2}^{*}\left(T^{*}\right)$ with Kihara potential.

TABLE I

\begin{tabular}{c|c|c|c|c|c|c|c|c|c|c}
\hline \hline \multirow{2}{*}{$a^{*}$} & \multicolumn{10}{|c}{$T^{*}$} \\
\cline { 2 - 11 } & 0.000 & $0.000^{a}$ & 0.111 & 0.144 & 0.0399 & 0.283 & 0.750 & 0.470 & 0.661 & 0.818 \\
\hline 0.50 & -8.72021 & -8.72021 & -7.30713 & -6.95861 & -8.16383 & -5.75048 & -3.42537 & -4.58775 & -3.74069 & -3.21053 \\
0.80 & -3.73423 & -3.73423 & -3.02712 & -2.85337 & -3.45533 & -2.25334 & -1.11018 & -1.67955 & -1.26417 & -1.00547 \\
1.00 & -2.53808 & -2.53808 & -2.00609 & -1.8755 & -2.32816 & -1.42494 & -0.568734 & -0.994782 & -0.683876 & -0.490484 \\
5.00 & 0.243344 & 0.243344 & 0.348585 & 0.374637 & 0.284714 & 0.465317 & 0.642146 & 0.553278 & 0.617927 & 0.6587 \\
10.0 & 0.460875 & 0.460875 & 0.527116 & 0.543767 & 0.486729 & 0.602633 & 0.722444 & 0.661289 & 0.705566 & 0.734081 \\
20.0 & 0.525374 & 0.525374 & 0.575458 & 0.588313 & 0.544729 & 0.634693 & 0.734234 & 0.682496 & 0.719749 & 0.744318 \\
40.0 & 0.518575 & 0.518575 & 0.562969 & 0.574595 & 0.535563 & 0.617351 & 0.713523 & 0.662774 & 0.699147 & 0.723607 \\
60.0 & 0.498213 & 0.498213 & 0.541629 & 0.553113 & 0.514745 & 0.595737 & 0.693742 & 0.641672 & 0.678914 & 0.70418 \\
80.0 & 0.47979 & 0.47979 & 0.523072 & 0.534591 & 0.49622 & 0.577591 & 0.677795 & 0.624337 & 0.662523 & 0.688565 \\
100 & 0.464069 & 0.464069 & 0.507445 & 0.519039 & 0.480498 & 0.562496 & 0.664719 & 0.610029 & 0.649061 & 0.675777 \\
\hline
\end{tabular}

${ }^{a}$ Ref. $[15,21]$

TABLE II

Comparison of the results obtained from Equation (9), different parameter values of Kihara potential [5, 22, 28], Lennard-Jones (12-6) potential and experimental data for Ar, Kr and Ne.

\begin{tabular}{|c|c|c|c|c|c|c|}
\hline \multirow{2}{*}{$T(K)$} & \multirow{2}{*}{ Eq. (9) } & \multicolumn{3}{|c|}{ Kihara Potential } & \multirow{2}{*}{$\begin{array}{c}\text { Lennard-Jones }(12-6) \\
\text { Potential }[15,21]\end{array}$} & \multirow{2}{*}{$\begin{array}{r}\text { Experimental } \\
\text { data }[22,30]\end{array}$} \\
\hline & & Ref. [28] & Ref. [5] & Ref. [20] & & \\
\hline \multicolumn{7}{|c|}{$\mathrm{Ar}$} \\
\hline 105.50 & -165.942 & -165.233 & -165.782 & -165.91 & -168.494 & -167.8 \\
\hline 143.16 & -94.6455 & -94.0733 & -94.3283 & -94.6238 & -97.7984 & -94.4 \\
\hline 153.16 & -83.2272 & -82.7287 & -82.9498 & -83.2071 & -86.1042 & -82.9 \\
\hline 203.16 & -46.4436 & -46.2832 & -46.3586 & -46.4292 & -47.684 & -46.5 \\
\hline 223.16 & -37.2241 & -37.1725 & -37.2333 & -37.2111 & -37.8735 & -37.3 \\
\hline 305.00 & -13.9107 & -14.1748 & -14.2097 & -13.9013 & -12.756 & -15.8 \\
\hline 601.00 & 12.9958 & 12.3132 & 12.2924 & 13.0007 & 16.6258 & 13.2 \\
\hline 700.00 & 16.3830 & 15.6482 & 15.6288 & 16.3874 & 20.3131 & 15.8 \\
\hline 800.00 & 18.8215 & 18.0508 & 18.0327 & 18.8255 & 22.9519 & 17.2 \\
\hline 900.00 & 20.6230 & 19.8272 & 19.8104 & 20.6266 & 24.8869 & 19.8 \\
\hline 1000.0 & 21.9923 & 21.179 & 21.1633 & 21.9957 & 26.3449 & 22.4 \\
\hline \multicolumn{7}{|c|}{$\mathrm{Kr}$} \\
\hline 114 & -340.417 & -340.306 & -339.624 & -339.963 & -321.522 & -363 \\
\hline 124 & -289.28 & -289.119 & -288.335 & -288.832 & -277.909 & -306 \\
\hline 145 & -215.389 & -215.278 & -214.46 & -215.073 & -212.1 & -229 \\
\hline 153 & -194.951 & -194.84 & -194.038 & -194.658 & -193.212 & -201 \\
\hline 174 & -153.647 & -153.536 & -152.803 & -153.401 & -154.057 & -158 \\
\hline 203 & -115.117 & -115.006 & -114.382 & -114.915 & -116.251 & -117 \\
\hline 255 & -73.3739 & -73.263 & -72.8115 & -73.221 & -73.777 & -75.6 \\
\hline 305 & -49.4342 & -49.3233 & -48.9961 & -49.3096 & -48.6695 & -50.7 \\
\hline 403 & -22.4927 & -22.3817 & -22.2168 & -22.4005 & -19.7628 & -21.9 \\
\hline 502 & -7.41916 & -7.30823 & -7.24396 & -7.34544 & -3.31801 & -8.09 \\
\hline 704 & 8.70138 & 8.81231 & 8.76247 & 8.75495 & 14.4076 & 7.09 \\
\hline \multicolumn{7}{|c|}{$\mathrm{Ne}$} \\
\hline 78.9 & -13.9365 & & & -13.9395 & -12.3588 & -12.6 \\
\hline 99.2 & -6.05633 & & & -6.05877 & -4.97303 & -6.38 \\
\hline 100 & -5.82062 & & & -5.82305 & -4.75168 & -6.0 \\
\hline 125 & -0.166542 & & & -0.168503 & 0.563254 & -0.157 \\
\hline 148 & 3.14667 & & & 3.14499 & 3.68014 & 3.56 \\
\hline 200 & 7.50606 & & & 7.50475 & 7.77619 & 7.6 \\
\hline 300 & 11.1477 & & & 11.1467 & 11.1755 & 11.3 \\
\hline 400 & 12.6702 & & & 12.6694 & 12.5749 & 12.8 \\
\hline 600 & 13.819 & & & 13.8183 & 13.5941 & 13.8 \\
\hline
\end{tabular}


TABLE III

The comparative values of second virial coefficients with Kihara, Lennard-Jones (12-6) potentials and Eq. (9) for Ar, $\mathrm{Kr}, \mathrm{Ne}, \mathrm{CH}_{4}, \mathrm{C}_{6} \mathrm{H}_{6}, \mathrm{C}_{3} \mathrm{H}_{8}, n-\mathrm{C}_{4} \mathrm{H}_{10}$ and $n-\mathrm{C}_{5} \mathrm{H}_{12}$

\begin{tabular}{|c|c|c|c|c|c|c|}
\hline$T(K)$ & Eq.(9) & $\begin{array}{c}\text { Kihara } \\
\text { Potential [20] }\end{array}$ & $\begin{array}{c}\text { Lennard-Jones } \\
(12-6) \text { Potential } \\
\text { Ref. }[15,21]\end{array}$ & Eq.(9) & $\begin{array}{c}\text { Kihara } \\
\text { Potential [20] }\end{array}$ & $\begin{array}{c}\text { Lennard-Jones } \\
(12-6) \text { Potential } \\
\text { Ref. }[15,21]\end{array}$ \\
\hline & \multicolumn{3}{|r|}{ 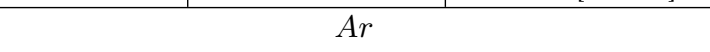 } & \multicolumn{3}{|c|}{$K r$} \\
\hline 100 & -182.99 & -182.99 & -184.846 & -443.157 & -443.157 & -404.842 \\
\hline 200 & -48.1068 & -48.1068 & -49.4462 & -118.413 & -118.413 & -119.536 \\
\hline 300 & -14.9128 & -14.9128 & -13.8442 & -51.3902 & -51.3902 & -50.7417 \\
\hline 400 & -0.244618 & -0.244618 & 2.14369 & -23.0879 & -23.0879 & -20.4085 \\
\hline 500 & 7.87632 & 7.87632 & 11.0303 & -7.65556 & -7.65556 & -3.57715 \\
\hline 600 & 12.9548 & 12.9548 & 16.5811 & 1.96648 & 1.96648 & 6.99359 \\
\hline 700 & 16.383 & 16.383 & 20.3131 & 8.48479 & 8.48479 & 14.1692 \\
\hline 800 & 18.8215 & 18.8215 & 22.9519 & 13.157 & 13.157 & 19.307 \\
\hline 900 & 20.623 & 20.623 & 24.8869 & 16.6456 & 16.6456 & 23.1311 \\
\hline \multirow[t]{2}{*}{1000} & 21.9923 & 21.9923 & 26.3449 & 19.3321 & 19.3321 & 26.0623 \\
\hline & \multicolumn{3}{|c|}{$\mathrm{Ne}$} & \multicolumn{3}{|c|}{$\mathrm{CH}_{4}$} \\
\hline 100 & -5.82062 & -5.82062 & -4.75168 & -429.901 & -429.901 & -373.085 \\
\hline 200 & 7.50606 & 7.50606 & 7.77619 & -105.905 & -105.905 & -108.62 \\
\hline 300 & 11.1477 & 11.1477 & 11.1755 & -42.0094 & -42.0094 & -42.8284 \\
\hline 400 & 12.6702 & 12.6702 & 12.5749 & -15.4109 & -15.4109 & -13.604 \\
\hline 500 & 13.4213 & 13.4213 & 13.2495 & -1.01061 & -1.01061 & 2.64038 \\
\hline 600 & 13.819 & 13.819 & 13.5941 & 7.92903 & 7.92903 & 12.8362 \\
\hline 700 & 14.0318 & 14.0318 & 13.7675 & 13.967 & 13.967 & 19.7442 \\
\hline 800 & 14.1391 & 14.1391 & 13.8443 & 18.2851 & 18.2851 & 24.6767 \\
\hline 900 & 14.1826 & 14.1826 & 13.8633 & 21.5034 & 21.5034 & 28.3355 \\
\hline \multirow[t]{2}{*}{1000} & 14.1861 & 14.1861 & 13.8465 & 23.978 & 23.978 & 31.1289 \\
\hline & \multicolumn{3}{|c|}{$\mathrm{C}_{6} \mathrm{H}_{6}$} & \multicolumn{3}{|c|}{$\mathrm{C}_{3} \mathrm{H}_{8}$} \\
\hline 100 & -201170 & -201164 & -100697 & -8404.14 & -8404.14 & -2909.57 \\
\hline 200 & -4993.56 & -4993.56 & -2703.32 & -948.528 & -948.528 & -798.825 \\
\hline 300 & -1457.68 & -1457.68 & -861.105 & -387.363 & -387.363 & -391.465 \\
\hline 400 & -719.333 & -719.333 & -464.585 & -209.415 & -209.415 & -222.152 \\
\hline 500 & -428.552 & -428.552 & -305.027 & -124.185 & -124.185 & -130.281 \\
\hline 600 & -277.3 & -277.3 & -220.715 & -74.6287 & -74.6287 & -73.0332 \\
\hline 700 & -185.612 & -185.612 & -168.987 & -42.3909 & -42.3909 & -34.187 \\
\hline \multirow[t]{2}{*}{800} & -124.443 & -124.443 & -134.147 & -19.8292 & -19.8292 & -6.25773 \\
\hline & \multicolumn{3}{|c|}{$n-C_{4} H_{10}$} & \multicolumn{3}{|c|}{$n-C_{5} H_{12}$} \\
\hline 100 & -44847.2 & -44847.2 & -5386.35 & -169997 & -169991 & -6847.16 \\
\hline 200 & -2095.05 & -2095.05 & -1348.06 & -4084.09 & -4084.09 & -1689.26 \\
\hline 300 & -711.03 & -711.03 & -666.946 & -1176.35 & -1176.35 & -835.682 \\
\hline 400 & -367.573 & -367.573 & -394.147 & -574.712 & -574.712 & -495.594 \\
\hline 500 & -220.857 & -220.857 & -248.477 & -338.882 & -338.882 & -314.411 \\
\hline 600 & -140.911 & -140.911 & -158.424 & -216.565 & -216.565 & -202.537 \\
\hline 700 & -90.9926 & -90.9926 & -97.562 & -142.562 & -142.562 & -126.976 \\
\hline 800 & -57.0096 & -57.0096 & -53.8787 & -93.2605 & -93.2605 & -72.7603 \\
\hline
\end{tabular}


TABLE IV

Convergence results of expression (9) and from [20] as a function of summation limits $N$

\begin{tabular}{c|c|c|c|c}
\hline \hline \multirow{2}{*}{$N$} & \multicolumn{2}{|c|}{$a^{*}=0.000$ and $T^{*}=100$} & \multicolumn{2}{c}{$a^{*}=0.818$ and $T^{*}=5$} \\
\cline { 2 - 5 } & Eq. (9) & Ref. [20] & Eq. (9) & Ref. [20] \\
\hline 5 & 0.4640692939053601 & 0.4640694857134132 & 0.6552290400583131 & 0.6589027966076112 \\
10 & 0.4640694689727591 & 0.4640694689728032 & 0.6586984866024695 & 0.6587001471269023 \\
15 & 0.46406946897280144 & 0.464069468972801 & 0.6587001004463544 & 0.6587001006874388 \\
20 & 0.46406946897280144 & 0.46406946897280105 & 0.6587001006829867 & 0.6587001006830022 \\
25 & 0.46406946897280144 & 0.46406946897280105 & 0.6587001006830024 & 0.6587001006830019 \\
30 & 0.46406946897280144 & 0.464069468972801 & 0.6587001006830024 & 0.6587001006830019 \\
35 & 0.46406946897280144 & 0.46406946897280105 & 0.6587001006830024 & 0.6587001006830018 \\
40 & 0.46406946897280144 & 0.46406946897280105 & 0.6587001006830024 & 0.6587001006830019 \\
45 & 0.46406946897280144 & 0.46406946897280105 & 0.6587001006830024 & 0.6587001006830018 \\
50 & 0.46406946897280144 & 0.46406946897280105 & 0.6587001006830024 & 0.6587001006830019
\end{tabular}

TABLE V

Parameters of Lennard-Jones (12-6) potencial and Kihara potencial

\begin{tabular}{|c|c|c|c|c|c|c|}
\hline \multirow[t]{2}{*}{ Gases } & \multicolumn{2}{|c|}{$\begin{array}{c}\text { Lennard-Jones } \\
(12-6) \text { potential }[15,34]\end{array}$} & \multicolumn{4}{|c|}{ Kihara potential $[27,28]$} \\
\hline & $\sigma[\AA]$ & $\varepsilon / k_{\mathrm{B}}[\mathrm{K}]$ & $a^{*}$ & $d[\AA]$ & $\sigma[\AA]$ & $\varepsilon / k_{\mathrm{B}}[\mathrm{K}]$ \\
\hline $\mathrm{Ar}$ & 3.623 & 111.84 & 0.111 & 0.33570 & 3.36 & 142.10 \\
\hline $\mathrm{Kr}$ & 3.895 & 154.87 & 0.144 & 0.44713 & 3.533 & 213.73 \\
\hline $\mathrm{Ne}$ & 2.75 & 35.6 & 0.0399 & 0.105 & 2.74 & 39.6 \\
\hline $\mathrm{CH}_{4}$ & 4.015 & 140.42 & 0.283 & 0.78569 & 3.562 & 227.13 \\
\hline $\mathrm{C}_{6} \mathrm{H}_{6}$ & 3.400 & 830.00 & 0.750 & 2.28686 & 5.336 & 832.00 \\
\hline $\mathrm{C}_{3} \mathrm{H}_{8}$ & 5.640 & 242.00 & 0.470 & 1.47427 & 4.611 & 501.89 \\
\hline$n-\mathrm{C}_{4} \mathrm{H}_{10}$ & 6.081 & 287.20 & 0.661 & 1.87714 & 4.717 & 701.15 \\
\hline$n-\mathrm{C}_{5} \mathrm{H}_{12}$ & 6.476 & 293.28 & 0.818 & 2.26277 & 5.029 & 837.82 \\
\hline
\end{tabular}
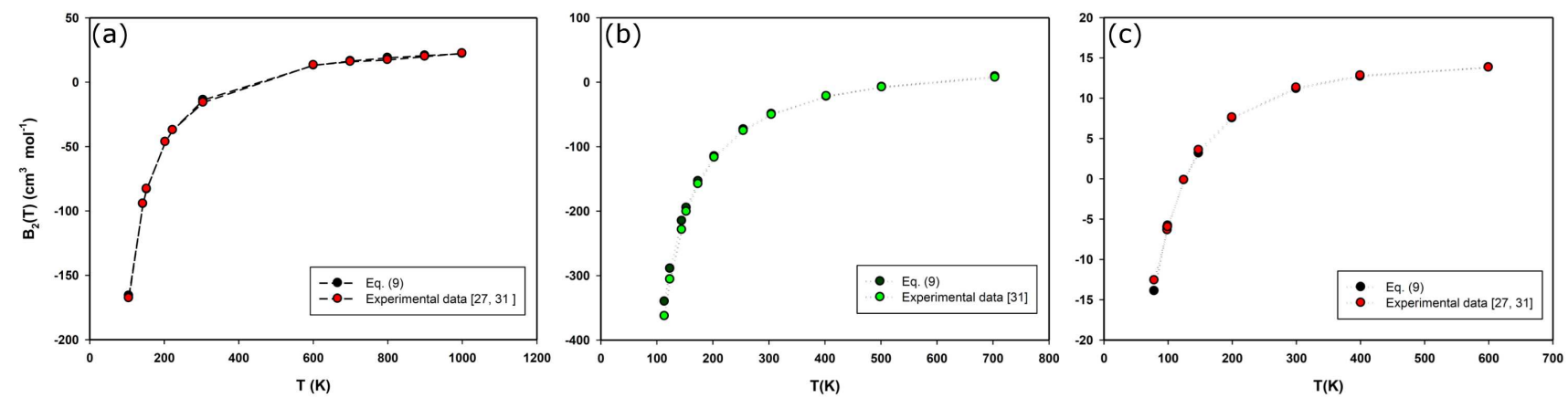

Fig. 2. The temperature dependence of second virial coefficients for: (a) Ar, (b) Kr, (c) Ne.

\section{Acknowledgments}

The authors wish to thank anonymous reviewers for their valuable comments. This work has been supported by the Scientific and Technological Research Council of Turkey (TUBITAK) Science Fellowships and Grant Programmes Department (BIDEB).

\section{References}

[1] I. Nezbeda, W.R. Smith, Fluid Phase Equilib. 216 , 183 (2004).

[2] C. Vega, C. McBride, C. Menduiña, Phys. Chem. Chem. Phys. 4, 3000 (2004).

[3] J.D. Dymond, K.N. Mash, R.C. Wilhoit, Virial Coefficients of Pure Gases and Mixtures, Springer, 2003. 
[4] J.E. Mayer, M.G. Mayer, Statistical Mechanics, Wiley, New York, 1948.

[5] A.E. Sherwood, J.M. Prausnitz, J. Chem. Phys. 41 429 (1964).

[6] S. Zhou, Mol. Simul. 33, 1187 (2007).

[7] T. Kihara, Y. Midzuno, S. Kaneko, J. Phys. Soc. Jap. 11, 362 (1956).

[8] Z. Eslami, S.A. Boushehri, Int. J. Therm. Sci. 42, 295 (2003).

[9] S.F. Ragab, A.A. Helmy, T.L. Hassanein, M.A. El-Naggar, J. Low. Temp. Phys. 111, 447 (1998).

[10] J. Tian, Y. Gui, J. Phys. Chem. 111, 10970 (2007).

[11] G. A. Parsafar, M. Shokouhi, Mol. Phys. 104, 3269 (2012).

[12] G. Garberoglio, P. Jankowski, K. Szalewicz, A.H. Harvey, J. Chem. Phys. 137, 154308 (2012).

[13] M.P. Hodges, R.J. Wheatley, G.K. Schenter, A.H. Harvey, J. Chem. Phys. 120, 710 (2004).

[14] M. Monajjemi, M. Khaleghian, F. Mollaamin, Mol. Simul. 36, 865 (2010).

[15] B.A. Mamedov, E. Somuncu, J. Mol. Struct. 1068, 164 (2014).

[16] B.A. Mamedov, E. Somuncu, Physica A 420, 246 (2015).

[17] G.J. Chen, C.Y. Sun, Chem. Eng. Sci. 56, 7045 (2001).

[18] K.W. Suh, T.S. Storvick, J. Phys. Chem. 71, 1450 (1967).
[19] P.K. Clayton, J. Chem. Edu. 60, 1063 (1983).

[20] L.S. Tee, S. Gotoh, W.E. Stewart, IEEC Fundamentals 5, 363 (1966).

[21] J.O. Hirschfelder, C.F. Curtiss, R.B. Bird, Molecular Theory of Gases and Liquids, Jonh Wiley \& Sons, 1954.

[22] W. Witschel, Int. J. Thermophys. 11, 1075 (1990).

[23] M. Deszczynski, S.E. Harding, D.J. Winzor, Biyophys. Chem. 120, 106 (2006).

[24] C. Haas, J. Drenth, W.W. Wilson, J. Phys. Chem. 103,2808 (1999).

[25] J.H. Dymond, Fluid Phase Equilib. 174, 13 (2000).

[26] D.A. McQuarine, Statistical Mechanics, Harper and Row, 1973.

[27] D.A. McQuarine, J.D. Simon, Phys. Chem.: A Mol. Approach (1997).

[28] J.M. Prausnitz, R.N. Lichtenthaler, E.G. de Azevedo, Molecular Thermodynamics of Fluid-Phase Equilibria, 3rd ed. Prentice Hall PTR, New Jersey, 1999.

[29] I.S. Gradshteyn, I.M. Ryzhik, Tables of Integrals, Series and Products, Academic press, London 1965.

[30] S.K. Oh, Korean J. Chem. Eng. 22, 949 (2005).

[31] A.E. Sherwood, J.M. Prausnitz, J. Chem. Phys. 41, 413 (1964).

[32] S.K. Oh, J. Thermodynamics 2013, 1 (2013).

[33] J.P. O'Connell, J.M. Prausnitz, J. Phys. Chem. 78, 632 (1968).

[34] F. Cuadros, I. Cachadına, Mol. Eng. 6, 319 (1996). 